\title{
Predicament in Repairing Aircraft Primary Composite Structures
}

\author{
By Mostefa BourchaK \\ Aeronautical Engineering Department, King Abdulaziz University, Jeddah, Saudi Arabia
}

(Received December 5th, 2012)

\begin{abstract}
Recently, composite materials have been introduced to commercial aircraft primary structures for the purpose of increased weight savings, reduction in corrosion, enhanced fatigue life and improved performance. However, repairing these primary structures can be very challenging to operators. A brief description is given about repairing aircraft nonprimary composite structures. More importantly, however, this paper discusses the current research carried out by major aerospace companies and their academic partners to develop reliable methods, tools and equipment for repairing aircraft primary composite structures. These new technologies aim to give the use of composite materials on "next-generation" commercial aircraft primary structures a more prominent advantage by addressing the issue of recurring costs due to maintenance.
\end{abstract}

Key Words: Composites Repair, Aircraft Primary Structures, Aircraft Maintenance

\section{Introduction}

Prior to the introduction of the Airbus A380 and Boeing Dreamliner B787 (and soon Airbus A350), composite materials usage was limited to the aircraft non-primary components. ${ }^{1)}$ This design decision made composite repairs in these components a trivial issue where repairs would usually be carried out at the workshop using mainly manual methods as indicated in Fig. 1. This process generally involves surface preparation, placing the fibers (sometimes with honeycomb structure) on the repair area, adding resin, and then the repair patch is vacuumed and heated with devices such as heat lamps or blankets. The repair patch is finally left to cure for a duration that is dependent on the resin type.

Composite repair patches have also been used successfully in repairing metal (mainly aluminum) structures. ${ }^{2}$ ) However, it has always been anticipated along the aircraft design stages that incorporating composite materials in primary structures would be highly challenging in terms of future damage repairs. This has already affected new aircraft designs such as the Mitsubishi Regional Jet (MRJ) that initially was intended to contain composite materials on primary structures but then designers reverted back to use of metal. ${ }^{3)}$ Bombardier also refrained from extensive composite use for its new CSeries aircraft and opted for metal instead (e.g., aluminum-lithium fuselage). Most recently, it was widely reported that composite delamination occurred in the newly commissioned Boeing 787 Dreamliners ${ }^{4}$ ) which led to further delays in deliveries of the famous composite aircraft seen in Fig. 2.

The delamination failure mechanism in composite materials similar to that shown in Fig. 3 has already been studied extensively by researchers ${ }^{5)}$ and aircraft manufacturers such as Boeing. ${ }^{6)}$ Unfortunately, the repair modifications to this

(C) 2013 The Japan Society for Aeronautical and Space Sciences

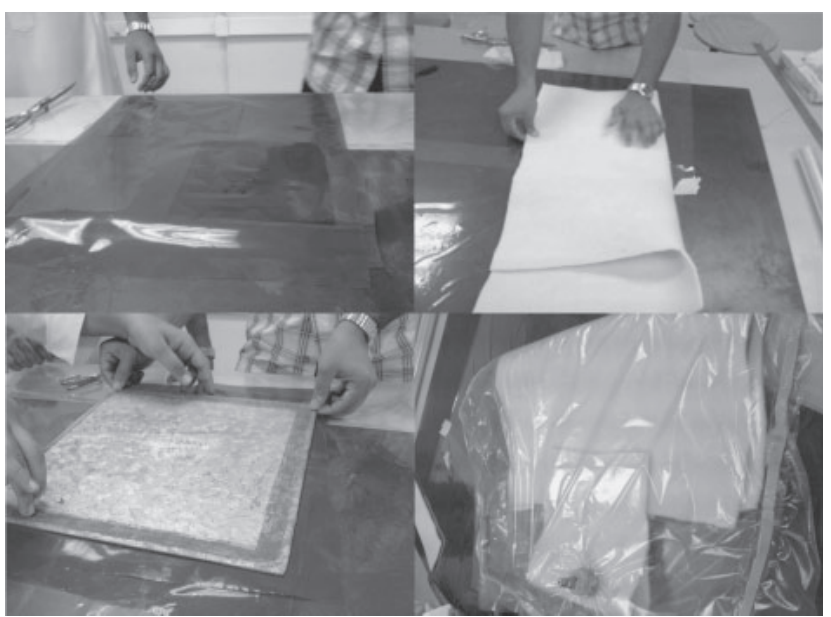

Fig. 1. Composite materials repair using vacuum bagging and wet layup.

composite failure mode would take a longer time due to current lack of relevant technologies for aircraft primary composite structures repair.

Additionally, it has only been a few years since the introduction of Airbus A380, but in 2012 the entire A380 fleet needed to be checked for wing ribs to skin attachment cracks. Although Airbus initially related this to a metal part that was not manufactured correctly, it later conceded that the design rectification turned out to be more complicated than initially anticipated and the final repair meant that all the wing composite ribs would be replaced with metal ones in 2013.7) In 2011, the US Government Accountability Office (GAO) identified four key safety-related concerns with the repair and maintenance of composites in commercial aircraft: limited information on the behavior of aircraft composite structures; technical issues related to the unique properties of composite materials; standardization of repair materials and techniques; and training and awareness. ${ }^{8)}$ Consequently, those reported failure issues occurring in load 


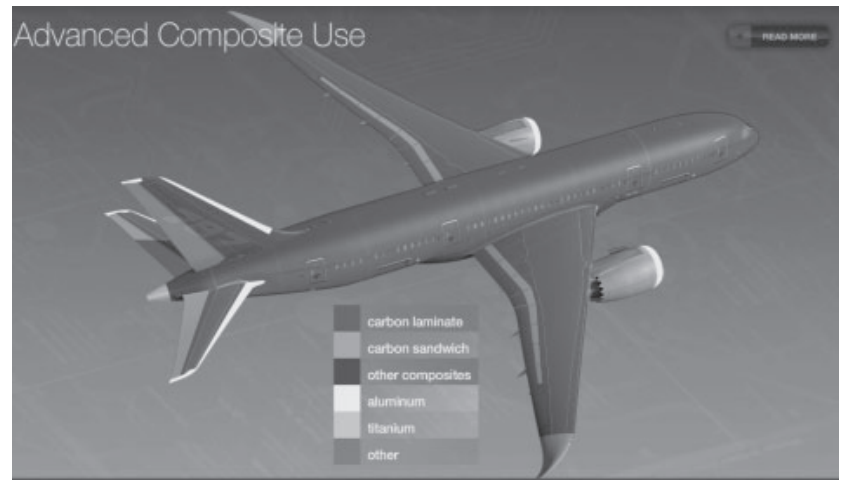

Fig. 2. Composite usage on Boeing 787 Dreamliner (Courtesy of Boeing).

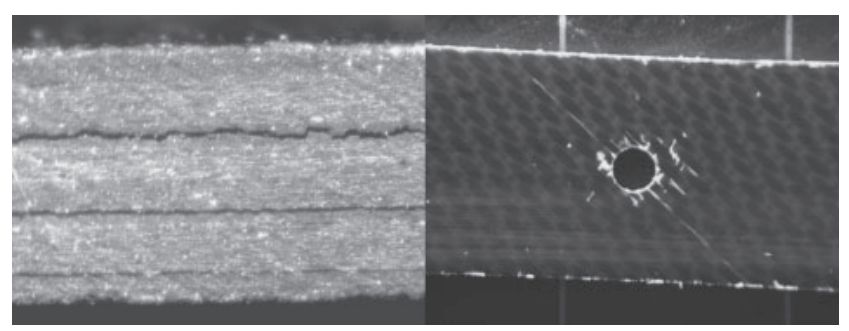

Fig. 3. Composite delamination (left: microscopic side view, right: around a notch using Dye Penetrant).

bearing critical composite structures made it inevitable that aircraft manufacturers such as Boeing and Airbus must put in place effective composite repair methods for primary load bearing structures in order to make the relevant aircraft safe and profitable to operators.

\section{Resin Curing Improvements}

Fortunately, scientists around the world have been paying attention to the issue of aircraft composite repair in primary structures. Recently, a consortium of US universities led by Wichita State University was awarded a grant by NASA to develop ways of better composite repairs. ${ }^{9}$ The researchers from this university argued that in current repair practice, resin is being cured at the wrong temperature band due to the use of thermocouples on the surface of the composite repair patch leading to an inability to estimate the mechanical properties during the cure cycle. Consequently they proposed a new approach where micro-size wireless temperature sensors (microwires) are to be used to monitor the cure temperature of the bondline and repair patch at different thicknesses inside the material. The obtained data would then be fed into viscosity models that determine the material state in real-time leading to the prediction of final mechanical properties of the repair.

Other related new innovations in composite repair resin curing have started to appear such as the HEATCON ${ }^{\circledR}$ stretchable heat blanket shown in Fig. 4, for repair of contoured surfaces, and the Zimac HBS Hot Bonder, which has multiple controllable heat source cells with feedback

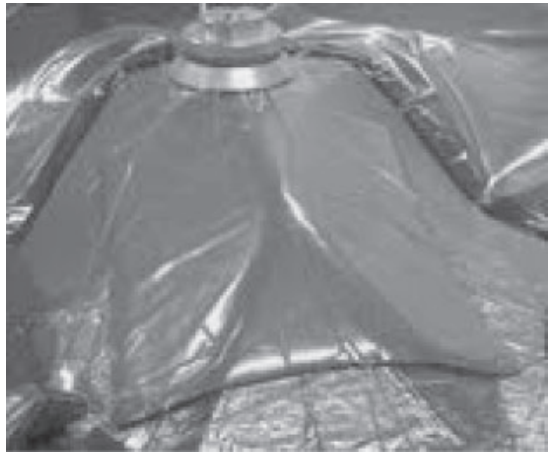

Fig. 4. HEATCON ${ }^{\circledR}$ flexible heat blanket (courtesy of HEATCON ${ }^{\circledR}$ ).

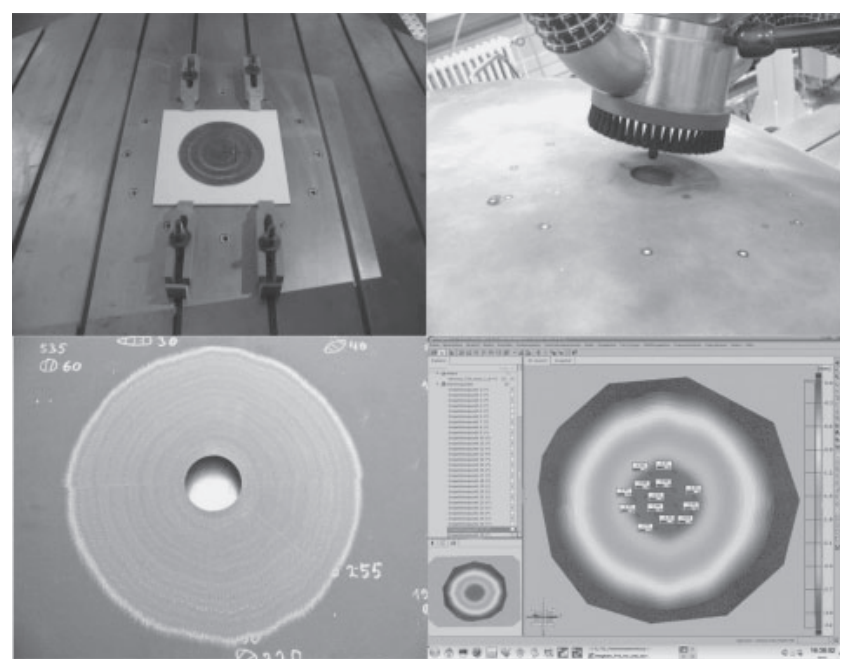

Fig. 5. 3D digitizing, milling and post milling digital scanning process to be integrated into one device (courtesy of EADS).

from multiple thermocouples.

Another innovation that is in use by NASA and Boeing is the Double Vacuum Debulking (DVD) technology which helps remove gasses and volatiles that are released from a composite repair patch while under the curing process.

\section{Automated Repair}

The introduction of composite aircraft such as the Dreamliner and the A350 resulted in thicker composite components than those seen in previous commercial aircraft. This big change required that composite repair be moved from a manual to an automated stage because of precision requirements and certification purposes. Funded research projects have already started producing prototypes of automated devices that incorporate non-destructive inspection (NDI), laser projection, three-dimensional (3D) digitizing, part machining, lay-up of pre-impregnated composite plies, and patch curing as detailed in Fig. 5. EADS is one of many companies that are currently leading the development of these composite repair automated devices.

To keep up with composite use in "next-generation" aircraft primary structures, international scientific forums ${ }^{10)}$ are being held to discuss the development of repair pro- 
cesses required to ensure aircraft safety. In addition, government agencies such as the Federal Aviation Administration (FAA) are developing new composite repair courses ${ }^{11)}$ to help aircraft manufacturers achieve the promise of maintenance cost savings in these "next-generation" composite aircraft.

\section{Conclusion}

Composite aircraft manufacturers and operators as well as third-party maintenance companies are racing to produce the tools and subsequent advanced training to carry out any future needs for repairing aircraft primary composite structures. Many promising and innovative devices are being developed. These devices make use of existing and new composite damage detection techniques as well as accurate measurement systems to develop automated devices that aim to reduce time and cost without compromising quality in repairing potential damage in aircraft primary composite structures. However, continuous and increased use of composite materials in commercial aircraft is partly dependent on the success of these new repair methods since metal aircraft require simpler efforts for damage repair in aircraft primary structures.

\section{References}

1) Jian, X. and Yao, L.: Study on Airworthiness Requirements of Composite Aircraft Structure for Transport Category Aircraft in FAA, Procedia Engineering, 17 (2011), pp. 270-278.

2) Goulios, G. and Marioli-Riga, Z.: Composite Patch Repairs for Commercial Aircraft: COMPRES, Air Space Eur., 3, 3-4 (2001), pp. 143-147.

3) Abe, T.: Composite Application Challenge in Primary Aircraft Structures, ICAS Workshop, Stockholm, 2011.

4) Seattle Times Business Staff: Boeing: 787 Delamination Fix Will Take "Days, Not Months," The Seattle Times, 2012.

5) Krueger, R. and O'Brien, T. K.: A Shell/3D Modeling Technique for the Analysis of Delaminated Composite Laminates, Composites Part A, 32, 1 (2001), pp. 25-44.

6) Gibson, G. E.: Fracture Analysis of Bondlines and Interfaces of Composite Structures, 4th International Conference of Composites Testing \& Model Identification, Dayton, 2008.

7) Goold, I.: Airbus Aims to Put A380 Wing Crack Problem behind It with Final Fix, AINonline, 2011.

8) United States Government Accountability Office (GAO): Aviation Safety: Status of FAA's Actions to Oversee the Safety of Composite Airplane, GAO-11-849, 2011.

9) Minaie, B.: Cure Management for Bonded Composite Repair, Department of Mechanical Engineering, Wichita State University, 2011.

10) Trew, J. (Aviation Week): Aircraft Composite Repair Management Forum, Amsterdam, 2012.

11) Ilcewicz, L., Cheng, L., Hafenricher, J. and Seaton, C.: Guidelines for the Development of a Critical Composite Maintenance and Repair Issues Awareness Course, US Department of Transportation, FAA, DOT/FAA/AR-08/54, 2009. 